trung bình của chỉ số HOMA2-IR của nhóm ĐTÐ typ 2 là $2.92 \pm 1.75$ (Bảng 3.7) cao hơn nhóm chứng có ý nghĩa thống kê với $p<0.05$ và cao hơn tứ phân vị trên của nhóm chứng là 1.78

Nồng độ IL-6 huyết tương và chỉ số HOMA2IR ở nhóm có chỉ số $B M I \geq 23$ cao hơn nhóm còn lại, sự khác biệt có ý nghĩa thống kê với $p<0.05$. Kết quả trên tương đồng với kết quả trong nghiên cứu của Rajeev Goyal và cộng sự

Trong nghiên cứu của chúng tôi cũng khảo sát mối liên quan giữa nồng độ IL-6 huyết tương với chỉ số HOMA2-IR và một số chỉ số hoa sinh cơ bản. Kết quả nghiên cứu cho thấy mối tương quan thuận, mức độ tương quan chặt giữa nồng độ IL-6 huyết tương với chỉ số HOMA2-IR điều này phù hợp với kết quả nghiên cứu của Kern và cộng sự năm $2001^{7}$. Ngoài ra kết quả nghiên cứu cững thể hiện mối tương quan thuận giữa nồng độ IL-6 huyết tương với các chỉ số BMI, HbA1c và nồng độ Glucose máu lúc đói.

\section{KẾT LUẬN}

Khi khảo sát nồng độ IL-6 huyết tương và chỉ số HOMA2-IR trên bệnh nhân ĐTĐ typ2 tại Bệnh viện Bạch Mai từ tháng 3/2020 đên tháng 10/2021, chúng tôi đưa ra một số kết luận sau:

Có sự khác biệt giữa nồng độ IL-6 huyết tương và chỉ số HOMA2-IR giữa nhóm bệnh và nhóm chứng, giữa nhóm béo phì và không béo phì.

Có mối tương quan thuận, mức độ tương đối chặt giữa nồng độ IL-6 huyết tương với chỉ số
HOMA2-IR và nồng độ Glucose máu lúc đói, $\mathrm{HbA1C.}$

\section{TÀI LIÊU THAM KHẢO}

1. Freeman AM, Pennings N. Insulin Resistance. In: StatPearls. StatPearls Publishing; 2021. Accessed July 31, 2021. http://www.ncbi.nlm.nih.gov/books/NBK507839/

2. Inchiostro $\mathbf{S}$. Measurement of insulin sensitivity in Type 2 diabetes mellitus: comparison between KITT and HOMA-\% $S$ indices and evaluation of their relationship with the components of the insulin resistance syndrome. Diabetic medicine. 2005;22(1):39-44.

3. Lehrskov LL, Christensen RH. The role of interleukin-6 in glucose homeostasis and lipid metabolism. Semin Immunopathol. 2019;41(4): 491-499. doi:10.1007/s00281-019-00747-2

4. Akbari M, Hassan-Zadeh V. IL-6 signalling pathways and the development of type 2 diabetes. Inflammopharmacology. 2018;26(3):685-698. doi:10.1007/s10787-018-0458-0

5. Marques-Vidal $\mathbf{P}$, Bastardot $F$, von Känel $\mathbf{R}$, et al. Association between circulating cytokine levels, diabetes and insulin resistance in a population-based sample (CoLaus study). Clin Endocrinol (Oxf). 2013; 78(2):232-241. doi:10.1111/j.1365-2265.2012.04384.x

6. Goyal $R$, Faizy AF, Siddiqui SS, Singhai $M$. Evaluation of TNF-a and IL- 6 Levels in Obese and Non-obese Diabetics: Pre- and Postinsulin Effects. N Am J Med Sci. 2012;4(4):180-184. doi:10.4103/1947-2714.94944

7. Kern PA, Ranganathan S, Li C, Wood L, Ranganathan G. Adipose tissue tumor necrosis factor and interleukin-6 expression in human obesity and insulin resistance. Am J Physiol Endocrinol Metab. 2001;280(5):E745-751. doi:10.1152/ajpendo.2001.280.5.E745

\title{
BÁO CÁO CA LÂM SÀNG PHẪU THUÂTT THÀNH CÔNG ĐIỀU TRI RÒ NộI MẠCH TYPE 1A SAU PHẪU THUÂ̂T VÒI VOI CẢI TIẾN
}

\section{TÓM TẮT}

Rò nội mạch sau đặt ống ghép nội mạch là biến chứng điển hình, trong đó rò nội mạch type $1 \mathrm{~A}$ cần được theo dõi và xử lý sớm vì có nguy cơ gây võ túi phình. Trong giai đoạn đâu thực hiện kỹ thuật vòi voi cải tiến của Bệnh viện Hữu nghị Việt Đức chúng tôi không thực hiện khâu ép thành quai động mạch chủ sau thân cánh tay đâu vào vỏ của ống ghép, vì vậy có 2 ca xuất hiện rò nội mạch type $1 A$ sau mổ. Trong quá trình theo dõ̃i có 01 ca bệnh mức độ rò tăng lên và

*Bênh viện Hữu Nghi Việt Đức, Trường đại học Y Hà Nội Chịu trách nhiệm chính: Phạm Hữu Lư

Email: thachluu76@gmail.com

Ngày nhận bài: 2.8.2021

Ngày phản biện khoa học: 27.9.2021

Ngày duyệt bải: 4.10.2021

\section{Phùng Duy Hồng Sơn*, Phạm Hũu Lư*}

nguy cơ võ̃ cao, bệnh nhân này đã được phẫu thuật khâu lỗ rò và cho kết quả tốt. Chúng tôi thông báo ca bệnh này và hồi cứu y văn.

\section{SUMMARY}

\section{SURGICAL CLOSURE OF A TYPE 1A ENDOLEAK AFTER FROZEN ELEPHANT} TRUNK PROCEDURE: A CASE REPORT

Endoleaks are specific complications after thoracic aortic endovascular repair, in these endoleak type $1 \mathrm{~A}$ is serious and require carefully follow up and treatment, because high risk of aneurysm rupture. In the initial time, that became apply Viet Duc University Hospital modification of frozen elephant trunk technique, we did not fix the wall of aortic arch behind brachiocephalic trunk to graft and there were two cases with endoleak type $1 \mathrm{~A}$ after surgery. In one 
case the endoleak flow was increased during follow up, the patient underwent successful surgical closure of endoleak. We report this case and review literatures.

\section{I. ĐĂT VẤN ĐỀ}

Phẫu thuật vòi voi cải tiến (Frozen Elephant Trunk-FET) đã là tiêu chuẩn vàng cho bệnh lý động mạch chủ (ĐMC) ngực khi cần xử lý thương tổn quai ĐMC và ĐMC xuống ${ }^{1}$. Có nhiều phương pháp cải tiến của kỹ thuật FET khác nhau và mỗi phương pháp có những biến chứng đặc trưng riêng. Nếu sử dụng vật liệu chuyên dụng như Thoraflex, Evita Open Plus thì không có biến chứng rò $Đ M C$ type $1 \mathrm{~A}$ do đã cắt và khâu đầu trên ĐMC vào ống ghép nội mạch toàn bộ chu $v^{1}{ }^{1}$. Coseli và cộng sự đã thông báo biến chứng rò nội mạch type $1 \mathrm{~A}$ ở bệnh nhân sự dụng phương pháp dùng ống ghép nội mạch và mạch nhân tạo rời, làm miệng nối xa kỹ thuật bán phần quai ĐMC2. Kỹ thuật cải tiến của Bệnh viện
Hữu nghị Việt Đức có nhiều ưu điểm và đã được áp dụng từ tháng $12 / 2019^{3}$, trong giai đoạn đầu thực hiện chúng tôi không thực hiện khâu ép thành quai động mạch chủ sau thẩn cánh tay đầu vào vỏ của ống ghép, vì vậy có 2 ca xuất hiện rò nội mạch type $1 \mathrm{~A}$ sau mổ ở vị trí này. Trong quá trình theo dõi ở 01 bệnh nhân dòng rò tăng lên và đã được phẫu thuật thành công khâu đường rò tháng 7/2021. Chúng tôi thông báo ca lâm sàng này và nhìn lại y văn.

\section{CA LÂM SÀNG:}

Bệnh nhân nam 57 tuổi, có tiền sử tăng huyết áp, được phẫu thuât FET ngày 21/04/2020 do lóc động mạch chủ type $A$ cấp tính. Diễn tiến sau mổ lần 1 thuận lợi, trên phim chụp cắt lớp vi tính (CLVT) trước ra viện có hình ảnh rò nội mạch type $1 \mathrm{~A}$ (hình 1 ) với dòng rò nhỏ.
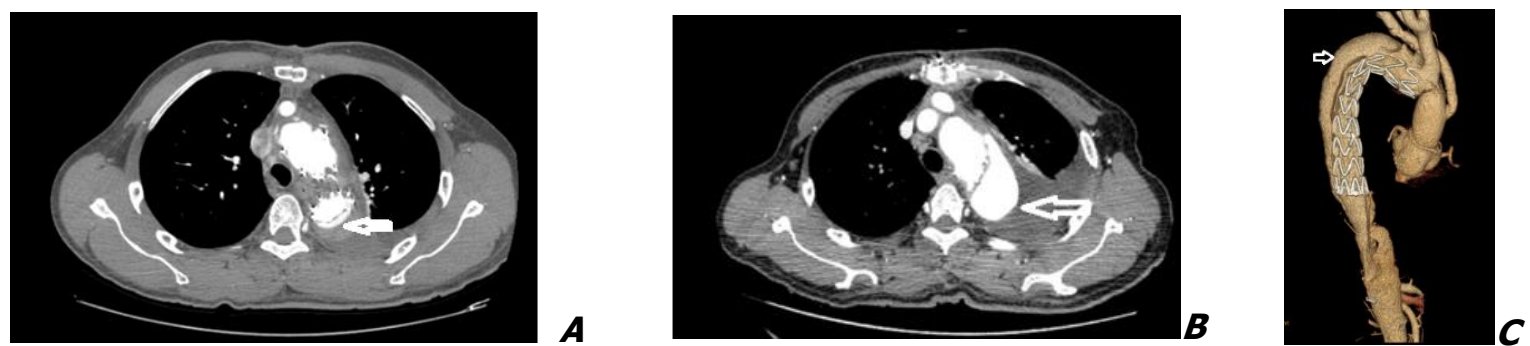

Hinh 1: Phim CLVT sau mổ

\section{A-Ngay sau mố- dòng rò nhỏ type 1A; B-sau 15 tháng- dòng rò tăng kích thước, dịch màng phổi trái; C- Phim dựng hình sau 15 tháng- dòng rò lớn}

Bn nhân được theo dõi và chụp lại phim CLVT sau 3 tháng và 6 tháng và 15 tháng thây mức độ rò tăng lên (hình1). Bệnh nhân được nhập viện điều trị. Khi nhập viện bệnh nhân có thể trạng tốt, đau ngực không thường xuyên. Nhóm ĐMC Trung tâm tim mạch và lồng ngực bệnh viện Hữu nghị Việt Đức đã hội chẩn và quyết định tiến hành mổ mở khâu đường rò.

Ngày 14/07/2021 bệnh nhân được phẫu thuật lại với chẩn đoán: Rò nội mạch type $1 \mathrm{~A}$ ở bệnh nhân sau phẫu thuật FET do lóc ĐMC type $A$. Trong mổ, bệnh nhẩn được mở lại xương ức, gõ dính, thiết lập tuần hoàn ngoài cơ thể qua canuyn thân cánh tay đầu và một canuyn tĩnh mạch vào nhĩ phải, hạ thân nhiệt $28^{\circ} \mathrm{C}$, tưới não chọn lọc 2 bên và ngừng tuần hoàn. Mở $\mathrm{DMC}$ ngang $2 \mathrm{~cm}$, ngay chân thân cánh tay đầu. Phần vỏ của ống thông ngay nửa sau chu vi thân cánh tay đầu được khâu ép vào thành quai ĐMC bằng chỉ prolen 4-0 có đệm kiểu "bánh kẹp" (hình 2A). Khâu mũi vắt prolen $5-0$ tăng cường phía trong ĐMC (hình 2B). Đóng đường mở và phục hồi lại tuần hoàn ngoài cơ thể, phục hồi lại tim và kết thúc cuộc mổ như thường quy. Thời gian ngừng tuần hoàn là 18 phút, thời gian mổ 4 giờ. Sau mổ diễn tiến thuận lợi, bệnh nhân được rút nội khí quản sau 10 giờ và ra viện sau 10 ngày.
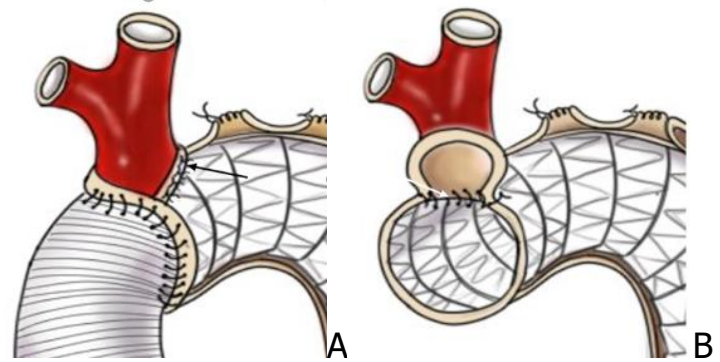

Hình 2: Minh họa kỹ thuật khâu đường rò trong mổ

A- Khâu ép thành ĐMC với ống ghép nội mạch có đệm (mũi tên)

B- Khâu vắt trong lòng mạch giữa thành $Đ M C$ và ống ghép nội mạch (Mũi tển)

Phim CLVT sau mổ cho thấy rò đã được đóng kín hoàn toàn và lòng giả đã được huyết khối toàn bộ (hình 2). 


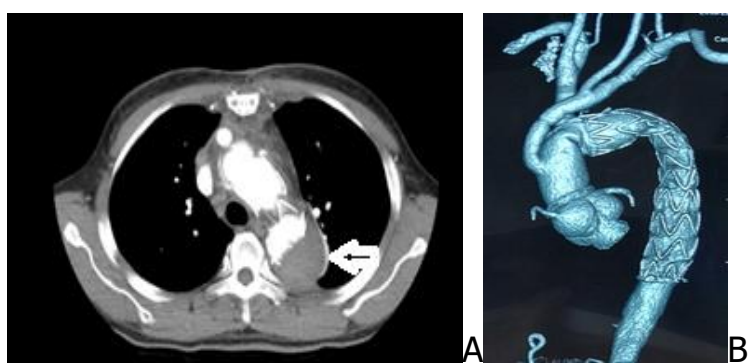

Hình 3: Phim CLVT sau mô: Huyêt khôi hoàn toàn lòng giả $(A)$ và đường rò đã được đóng kín (B).

\section{BÀN LUÂ̂N}

Rò nội mạch là biến chứng điển hình của can thiệp đặt ống ghép nội mạch và được định nghĩa là hiện tượng khi vẫn còn dòng máu chảy vào túi phình sau can thiệp đặt ống ghép nội mạch điều trị phình $Đ M C^{4,5}$. Theo thời gian xuất hiện rò nội mạch được chia làm hai loạí:

+ Rò nội mạch sớm hay nguyên phát là loại rò xuất hiện trong vòng 30 ngày sau can thiệp.

+ Rò nội mạch thứ phát hay muộn là các trường hợp rò xuất hiện sau 30 ngày.

Phân loại thường được sử dụng nhất là phân loại dựa trên nguồn gốc xuất phát của dòng máu vào túi phình. Theo đó, rò nội mạch được phân thành 5 loại như' sau"

1. Loại I: Rò từ cổ gần (IA) hoặc cổ xa của túi phình (IB).

2. Loại II: Rò từ các nhánh bên động mạch chủ vào túi phình như: động mạch thắt lưng, động mạch mạc treo tràng dưới, động mạch chậu trong.

3. Loại III: Rò từ chỗ hở giữa các khúc nối của ống ghép

4. Loại IV: Rò từ thân ống ghép

5. Loại V: (endotension): Tăng áp lực bên trong túi phình làm tăng kích thước phình, không thấy hình ảnh rò trên các phương tiện chẩn đoán hình ảnh.

Rò nội mạch type1 xảy ra do sự ép không chặt của ống ghép nội mạch vào thành động mạch chủ dẩn đến có dòng máu chảy vào túi phình từ đầu trên (type $1 A$ ) hoặc từ đầu dưới $(1 \mathrm{~B})^{6}$, với việc dòng máu thông vào túi phình hay lòng giả gây nguy cơ phát triển và võ túi phình, do vậy loại rò này cần được điều trị 4,7 . Rò type 1 là biển chứng gặp với xác suất 3,3-16\% sau can thiệp nội mạch ĐMC $\mathrm{C}^{6}$. Thường rò nội mạch type $1 \mathrm{~A}$ được điều trị bằng can thiệp nội mạch như: nong bóng đầu trên giúp ống ghép nở ra và che kín, đặt thêm giá đõ ĐMC cho đoạn cổ gần, đặt thêm ống ghép nội mạch đoạn cổ gần (aortic cuff), bít bằng coil hoặc keo, kỹ thuật ống khói (chimney) hoặc chuyển mổ mởs,8. Nong bóng nội mạch hoặc đặt thêm giá đõ̃ nội mạch không phải khi nào cũng đóng kín được lỗ rò, còn đăt thêm ống ghép nội mạch chỉ thực hiện được khi còn vùng cổ túi phình phù hợp (Landing zone), kỹ thuật ống khói khá phức tạp và chi phí cao, kỹ thuật bơm keo hay bít coil có thể thực hiện được khi có kinh nghiệm và vật tư chuyên dụng ${ }^{6-8}$.

Trong trường hợp lầm sàng của chúng tôi, bệnh nhân được thực hiện kỹ thuật FET cách 15 tháng. Đầu trển của ống ghép nội mạch $3 / 4$ chu vi đã được khâu chặt với thành mạch và mạch nhân tạo, chỉ có phần phía sau xuất phát của thân động mạch cánh tay đầu chưa được cố định vào thành $Đ M C$ nên xẩy ra rò. Vì lý do này nên nong bóng xác suất cao là không đóng được đường rò, do vậy chúng tôi không tiến hành nong bóng. Ở vị trí này cũng không còn cổ túi phình (landing zone) nên không thể đă̆t thêm ống ghép nội mạch, phần khác do khả nắng kinh tế của bệnh nhân có hạn nên phương pháp Chimney hay bít đường rò cũng không được đặt ra. Chúng tôi với lợi thế là trung tâm ngoại khoa chuyên ngành nển quyết định mổ mở đóng đường rò. Về mặt kỹ thuật mổ khâu đóng đường rò không quá phức tạp, tuy nhiên đây là biện pháp xầm lấn. Ca lâm sàng này nhằm đưa thông báo phẫu thuật như một lựa chọn an toàn, hiệu quả cho đóng đường rò sau can thiệp nội mạch khi các phương pháp can thiệp nội mạch khổng thể thực hiện được.

\section{KẾT LUẬN}

Rò sau can thiệp nội mạch là biến chứng điển hình. Rò type 1cần được can thiệp sớm để tránh biến chứng võ̃ túi phình. Điều trị rò sau can thiệp mạch có nhiều biện pháp khác nhau, ưu tiên các phương pháp can thiệp nội mạch, trường hợp không thể can thiệp nội mạch thì phẫu thuật mổ mở cũng là một lựa chọn.

\section{TÀl LIÊU THAM KHẢO}

1. Czerny M, Schmidli J, Adler S, et al. Current options and recommendations for the treatment of thoracic aortic pathologies involving the aortic arch: an expert consensus document of the European Association for Cardio-Thoracic surgery (EACTS) and the European Society for Vascular Surgery (ESVS). Eur J Cardiothorac Surg. 2019;55(1):133-162. doi:10.1093/ejcts/ezy313

2. Roselli EE, Idrees JJ, Bakaeen FG, et al. Evolution of Simplified Frozen Elephant Trunk Repair for Acute DeBakey Type I Dissection: Midterm Outcomes. Ann Thorac Surg. 2018;105(3):749-755.

doi:10.1016/j.athoracsur.2017.08.037

3. Phung DHS, Nguyen TS, Pham VL, Doan QH, Nguyen HU. A novel modification of frozen 
elephant trunk technique: unique protocol from one institution. Eur Rev Med Pharmacol Sci 2021 2514 4738-4745 DOI 1026355 eurrev20210726384.

4. 2014 ESC Guidelines on the diagnosis and treatment of aortic diseases: Document covering acute and chronic aortic diseases of the thoracic and abdominal aorta of the adultThe Task Force for the Diagnosis and Treatment of Aortic Diseases of the European Society of Cardiology (ESC). Eur Heart J. 2014;35(41):2873-2926. doi:10.1093/ eurheartj/ehu281

5. Ricotta Jj. Endoleak management and postoperative surveillance following endovascular repair of thoracic aortic aneurysms. J Vasc Surg.
2010;52(4):91S-99S.

doi:10.1016/j.jvs.2010.06.149

6. Ameli-Renani $S$, Pavlidis $V$, Morgan RA. Secondary Endoleak Management Following TEVAR and EVAR. Cardiovasc Intervent Radiol. 2020; 43(12):1839-1854. doi:10.1007/s00270-020-02572-9

7. Parmer SS, Carpenter JP, Stavropoulos SW, et al. Endoleaks after endovascular repair of thoracic aortic aneurysms. J Vasc Surg. 2006;44(3):447452. doi:10.1016/j.jvs.2006.05.041

8. Chen J, Stavropoulos SW. Management of Endoleaks. Semin Interv Radiol. 2015;32(3):259264. doi: $10.1055 / \mathrm{s}-0035-1556825$

\title{
KẾT QUẢ XẠ TRỊ 3D-CRT VÀ VMAT TRONG HOÁ XẠ ĐỒNG THỜI UNG THƯ THỰC QUẢN TẠI BỆNH VIỆN K
}

\author{
Nguyễn Thanh Tùng ${ }^{1}$, Võ Văn Xuân ${ }^{2}$
}

\section{TÓM TẮT}

Mục tiêu: Mô tả một số đặc điểm lâm sàng, cận lâm sàng và đánh giá kết quả xạ trị bằng kỹ thuật 3DCRT và VMAT ở bệnh nhân hoá xạ đồng thời ung thư thực quản tại bệnh viện $K$. Đối tượng và phương pháp nghiên cứu: Nghiên cứu mô tả hồi cứu kết hợp tiến cứu trên 60 bệnh nhân điều trị hoá xạ đồng thời ung thư thực quản bằng kỹ thuật 3D-CRT và VMAT tại bênh viên $K$ từ tháng $5 / 2018$ đến tháng $5 / 2021$. Kểt quả: Tuổi trung bình 54,4 $\pm 7,0$ (43-69). Tỷ lệ nam/nũ là 59/1. Tỷ lệ nuốt nghẹn $91,7 \%$. Có 46 (76,7\%) bệnh nhân giai đoạn T3, 14 (23,3\%) bệnh nhân ở giai đoạn T4. Thể giải phẫu bênh của các bệnh nhân là ung thư biểu mô vảy $(100 \%)$. Các thông số bao phủ liều đến PTV (thể tích xạ kế hoạch - Planning target volume) của xạ trị VMAT so với 3D-CRT: V95: $98,4 \%$ 94,35\%, V110: 0,15\% - 5,35\%. Dmax tại tuỷ và da VMAT thấp hơn so với 3D-CRT. Liều tại phổi $(\mathrm{V} 5, \mathrm{~V} 20)$ và tại tim (V40) VMAT thấp hơn so với 3D-CRT.Tỷ lệ đáp ứng toàn bộ sau hóa xa trị là $48,3 \%$, tỷ lệ đáp ứng 1 phân là $41,7 \%$, tỷ lệ bệnh không đổi là $10 \%$. Đốc tính trên hệ huyết học là hạ bach câu $(6 \%)$, hạ tiểu câu $(1,7 \%)$. Độc tính viêm da do xạ trị $(58,4 \%)$, viêm thực quản do xạ trị $(18,3 \%)$, độc tính viêm phổi do xạ trị $(3,3 \%)$, không ghi nhận độc tính trên hệ tim mạch. Kết luân: Xa trị ung thư thực quản bằng kỹ thuật VMAT và 3D-CRT cho kết quả tốt và an toàn, kỹ thuật VMAT cho thây tập trung liều xạ tốt hơn và ít độc tính hơn kỹ thuật 3D-CRT.

Tư khóa: ung thư thực quản, hóa xạ trị đồng thời, kỹ thuật 3D-CRT, kỹ thuật VMAT

\section{${ }^{1}$ Trường Đại học Y Hà Nội \\ ²Bênh viện $K$}

Chịu trách nhiệm chính: Nguyễn Thanh Tùng

Email: dr.tungnguyen710@gmail.com

Ngày nhận bài: 26.7.2021

Ngày phản biện khoa học: 27.9.2021

Ngày duyệt bài: 1.10.2021

\section{SUMMARY}

THE RESULTS OF 3D-CRT VS VMAT IN CONCURRENT CHEMORADIOTHERAPY FOR ESOPHAGEAL CANCER

Objective: Describe some clinical and paraclinical characteristics and evaluate the results of radiaotherapy by 3D-CRT and VMAT techniques in patients with concurrent chemoradiotherapy with esophageal cancer at K hospital. Subjects ad methods: A retrospective and prospective descriptive study on 60 patients undergoing concurrent chemoradiotherapy for esophageal cancer with 3DCRT and VMAT techniques at $\mathrm{K}$ hospital from May 2018 to May 2021. Results: Mean age $54.4 \pm 7.0$ (43-69). The male/female ratio is $59 / 1$. Swallowing rate $91.7 \%$. There are $46(76.7 \%)$ patients at T3 stage, $14(23.3 \%)$ patients at T4 stage. The histopathology of the patients was squamous cell carcinoma $(100 \%)$. Parameters of dose coverage to PTV (planning target volume) of VMAT radiotherapy compared with 3D-CRT: V95: $98.4 \%$ - 94.35\%, V110: $0.15 \%-5,35 \%$. Dmax at marrow and skin VMAT is lower than 3D-CRT. The dose in the lungs $(\mathrm{V} 5, \mathrm{~V} 20)$ and at the heart (V40) of VMAT was lower than that of 3D-CRT. The overall response rate after chemotherapy and radiotherapy was $48.3 \%$, the partial response rate was $41.7 \%$, the disease rate remained unchanged at $10 \%$. Hematologic toxicity was leukopenia (6\%), thrombocytopenia (1.7\%). Radiation-induced dermatitis $(58.4 \%)$ radiation-induced esophagitis $(18.3 \%)$, radiation-induced pneumonia toxicity (3.3\%), no cardiovascular toxicity was noted. Conclusion: Radiation therapy for esophageal cancer by VMAT and 3D-CRT techniques gives good and safe results, the VMAT technique shows better radiation dose concentration and less toxicity than 3D-CRT technique.

Keywords. Esophagus Cancer, concurrent chemoradiotherapy, 3D-CRT technique, VMAT technique.

\section{I. ĐĂT VẤN ĐỀ}

Theo GLOBOCAN 2018, ung thư thực quản 